\title{
Statistical Properties of Rayleigh Lomax distribution with applications in Survival Analysis
}

\author{
Kawsar Fatima, Uzma Jan and S.P Ahmad \\ Department of Statistics, University of Kashmir, Srinagar, India \\ Corresponding authors email: kawsarfatima@gmail.com ; peeruzmal@gmail.com
}

\begin{abstract}
The paper deals with the introduction of new generalized model i.e., Rayleigh Lomax distribution. In this manuscript, a comprehensive description of the various structural properties of the new proposed model including explicit expressions for moments, quantile function, generating functions and Renyi entropy have been given. The parameters of the newly developed distribution have been estimated using the technique of maximum likelihood estimation. Also, the generalized model has been compared with different models for illustration and best fit.
\end{abstract}

Keywords: Rayleigh Lomax Distribution, Reliability analysis, Moments, Order Statistics, Renyi Entropy, AIC, BIC and AICC.

\section{Introduction}

The Rayleigh and Lomax distributions are the versatile distributions existing in statistical literature. The Lomax (ParetoII) distribution was introduced by K.S. Lomax [1] to study business failure data. This model is widely applicable in several fields like reliability engineering, actuarial sciences, biological sciences and lifetime modeling. Bryson [2] suggested that this distribution can be an alternate to exponential distribution when the data is heavy detailed. Many authors used this distribution for modeling various data, for instance, Atkinson and Harrison [3] studied it for modeling business records, Hassan and Al Ghamidi [4] considered this model for reliability and life testing.

The Rayleigh model was first introduced by Lord Rayleigh in 1880.This distribution finds variety of applications in modeling lifetime data, survival analysis, clinical and agricultural studies and applied statistics. It is generally used in analyzing wind speed data. The two parameter Weibull distribution reduces to Rayleigh model when the shape parameter is equal to 2 . The genesis and the properties of this distribution were first studied by Siddiqui [5]. The different authors which have further discussed this model include Howlader and Hossain [6], Lalitha and Mishra [7] and Abd Elfattah [8].

\section{Rayleigh Lomax Distribution}

Many lifetime models have been introduced in the statistical theory to study the diverse fields including reliability engineering, demography, actuarial statistics, medical and biological sciences etc. However, the classical distributions sometimes fail to model certain real life phenomena. Thus, generalizing the continuous univariate distribution by adding an additional parameter such as location, scale and shape parameters to the parent distribution and subsequently analyze their influence on the shape of the baseline model. Several generalization techniques have been introduced in the statistical sciences which comprise of Malshal Olkin G by Marshall and Olkin [9], Kumaraswamy-G (K-G) by Cordeiro and de 
Castro [10], Beta-G by Eugene et al.[11], McDonald-G (Mc-G)by Alexander et al.[12], Transmutation technique by Shaw and Buckley[13] and Transformed- transformer (T-X) by Alzaatreh et al.[14]

In this article, we present a new extension of Lomax distribution called Rayleigh Lomax distribution using the generator technique. In the recent past, several authors have provided extensions of Lomax distributions such as Gumbel Lomax (GuLx), Weibull-Lomax (WL) by Tahir et al. [15,16], Exponential Lomax (EL) by El-Bassiouny et al. [17].

A random variable $\mathrm{X}$ has the Lomax distribution with two parameters $\theta$ and $\lambda$, if its cumulative distribution function (cdf) is given by:

$$
G(x)=1-\left(\frac{\theta}{\theta+x}\right)^{\lambda}
$$

where $\theta$ and $\lambda$ are the scale and shape parameters respectively. The distribution function of the Rayleigh Lomax model can be formulated as:

$$
F(x)=\int_{0}^{\frac{1}{1-G(x)}} \beta x e^{-\frac{\beta}{2} x^{2}} d x
$$

where $f(x)=\beta x e^{\frac{-\beta}{2} x^{2}}$ is the probability density function of one parameter Rayleigh distribution. Inserting eq (1) in eq (2), we get the distribution function of the new generalized distribution as

$$
F(x)=\int_{0}^{\left(\frac{\theta}{\theta+x}\right)^{-\lambda}} \beta x e^{-\frac{\beta}{2} x^{2}} d x
$$

Putting $\frac{\beta}{2} x^{2}=z, \beta x d x=d z$, when $x=0, z=0 ; x=\left(\frac{\theta}{\theta+x}\right)^{-\lambda}, z=\frac{\beta}{2}\left(\frac{\theta}{\theta+x}\right)^{-2 \lambda}$.

We have

$$
F(x)=1-e^{\frac{-\beta}{2}\left(\frac{\theta}{\theta+x}\right)^{-2 \lambda}}, x \geq-\theta \text { and } \theta, \lambda, \beta>0
$$

The graphical representation of cumulative function for different possible values of the parameters is shown in figure 1 which is always an increasing function

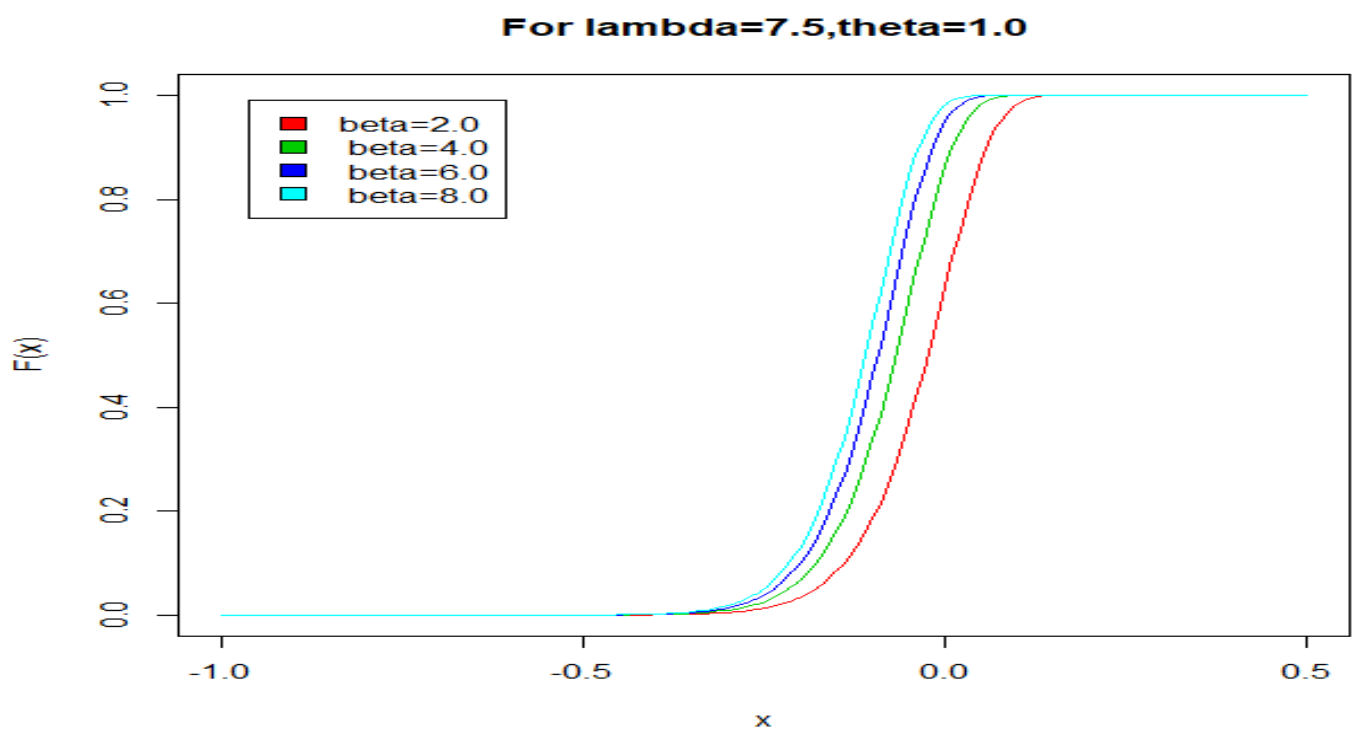

Figure1. Graph of distribution function 
For beta $=1.0$, theta $=0.5$

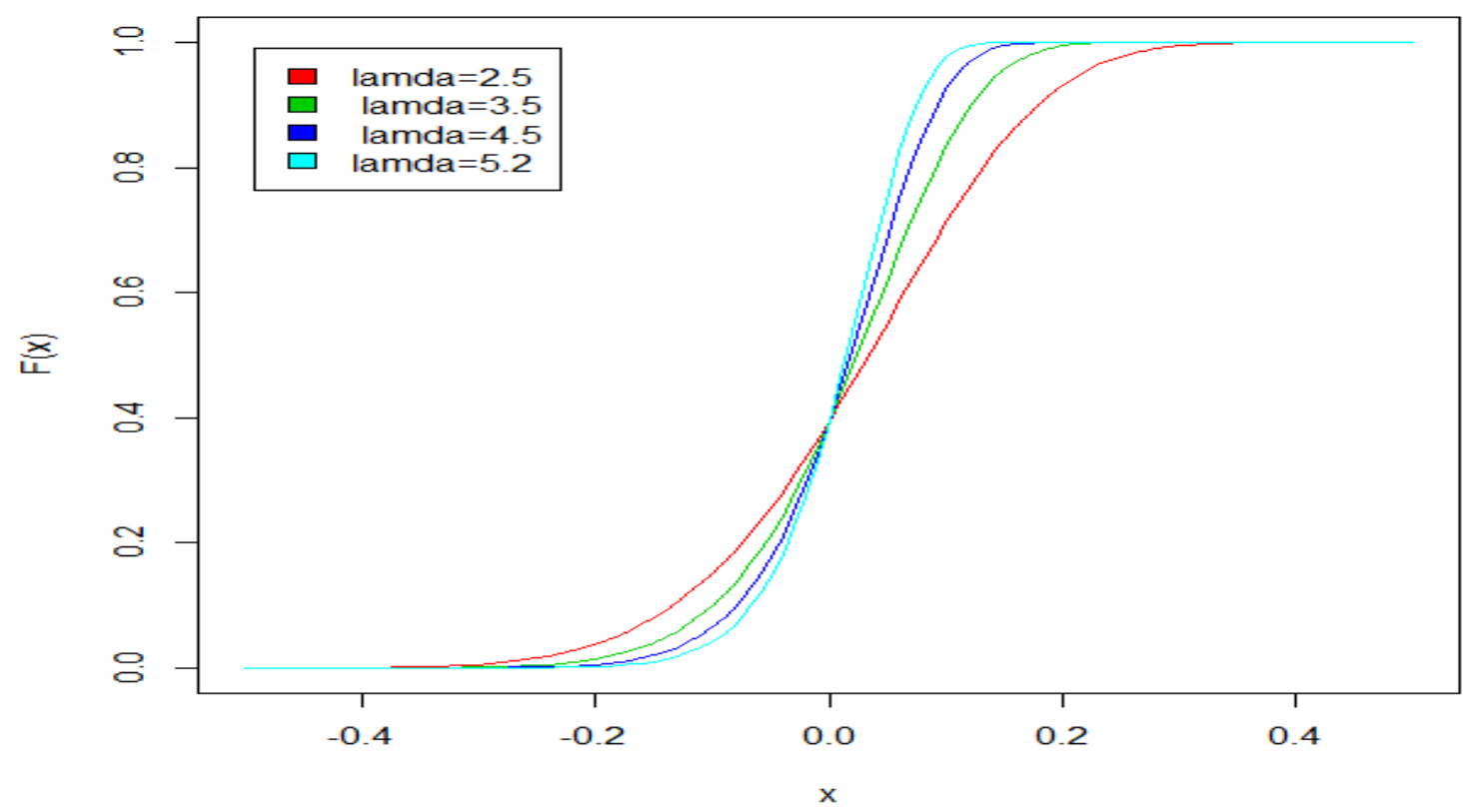

Figure1. Graph of distribution function

For beta=1.0,lamda $=1.2$

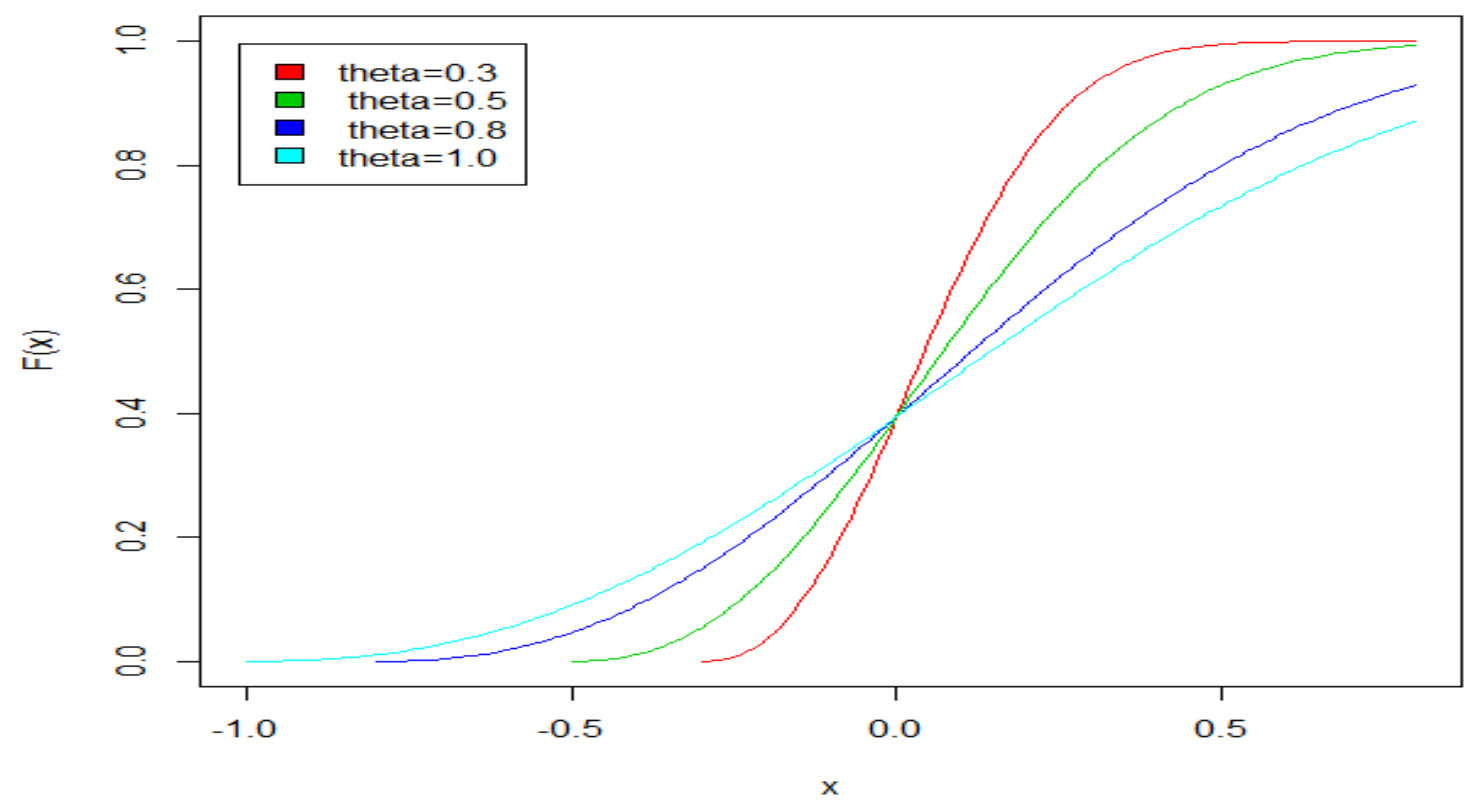

Figure1. Graph of distribution function

The corresponding probability density function of the Rayleigh Lomax function is as such given as:

$$
f(x, \beta, \lambda, \theta)=\frac{\beta \lambda}{\theta}\left(\frac{\theta}{\theta+x}\right)^{-2 \lambda+1} e^{-\frac{\beta}{2}\left(\frac{\theta}{\theta+x}\right)^{-2 \lambda}}, x \geq-\theta \text { and } \theta, \lambda, \beta>0 .
$$

The plots of probability density function for different values of the parameters are shown in figure 2 
For lambda $=7.5$, theta $=1.0$

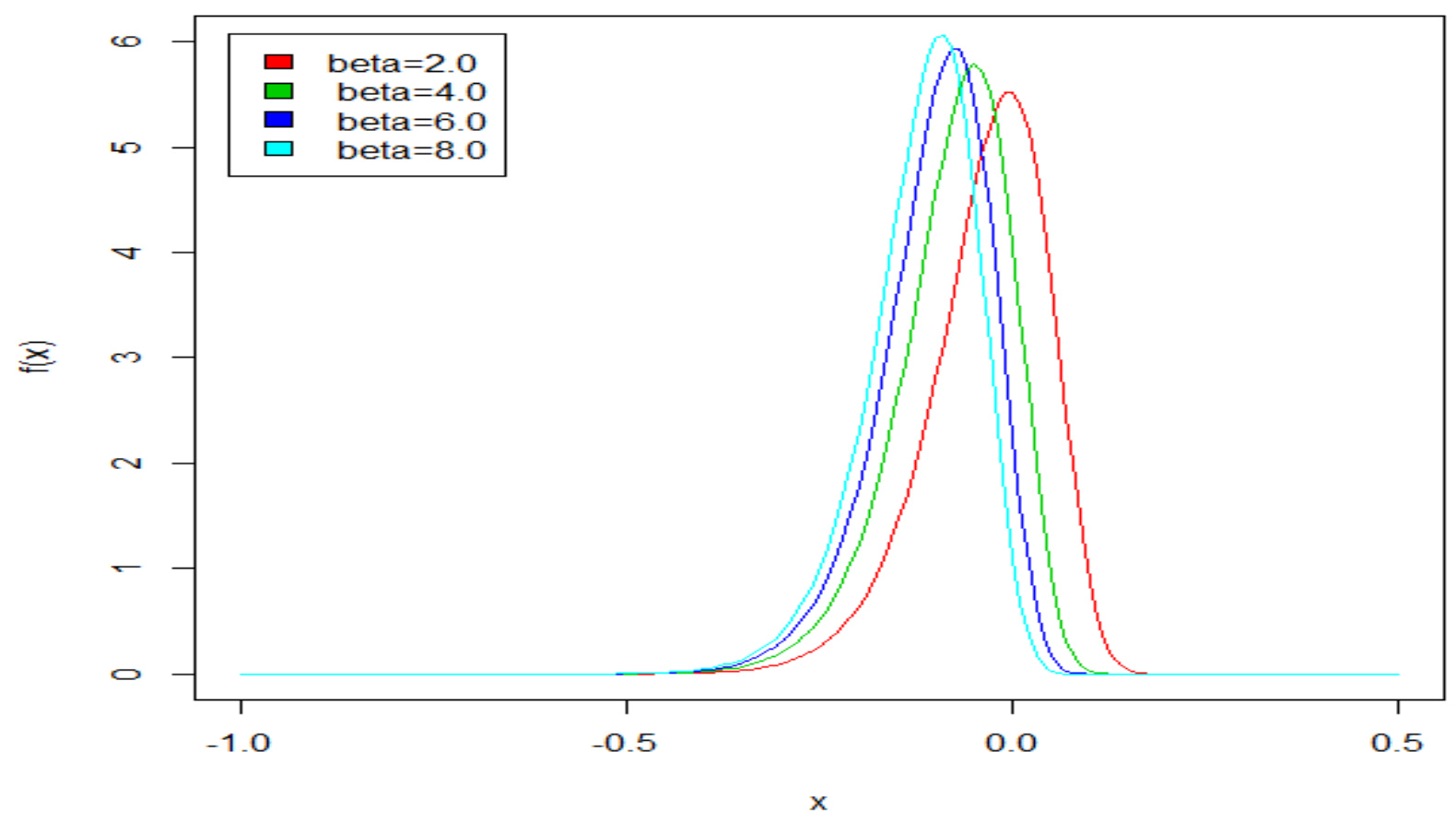

Figure2. Graph of distribution function

For beta $=1.0$, theta $=0.5$

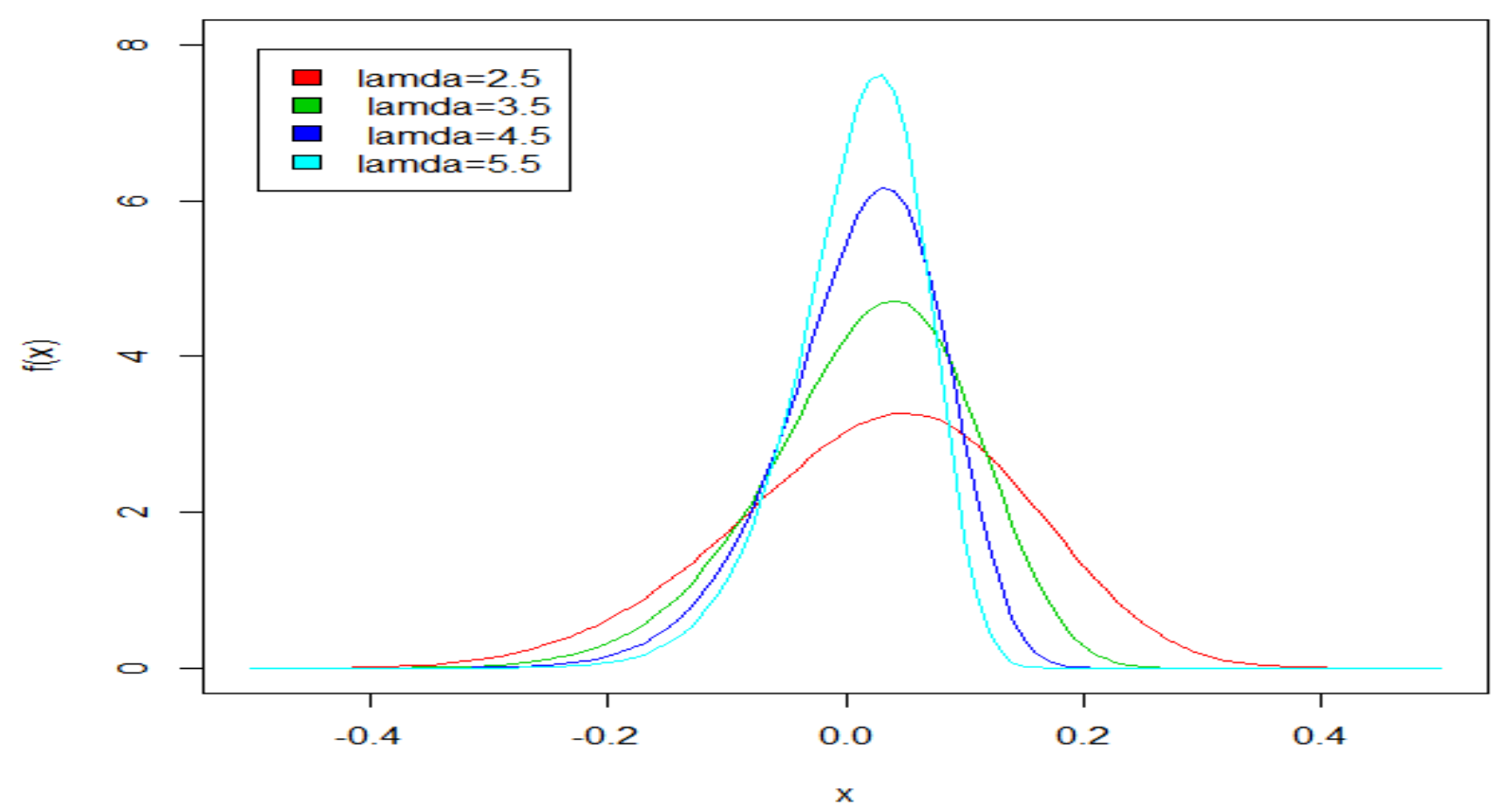

Figure2. Graph of distribution function 


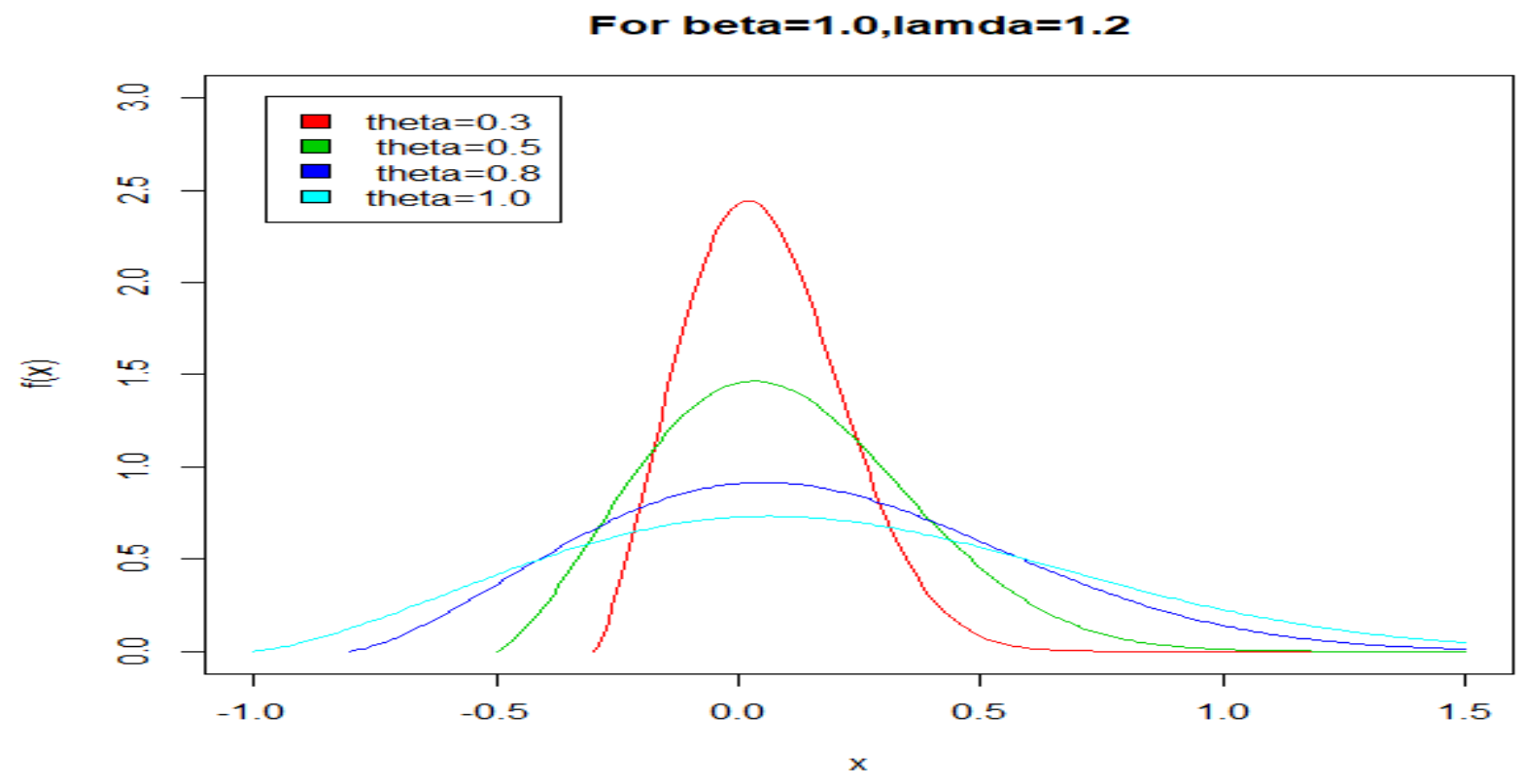

Figure2. Graph of distribution function

The rest of the paper is organized as follows: In section 3, the reliability measures of the proposed model are discussed. The section 4 deals with the different structural properties of the distribution including quantile function, moments, generating functions. A comprehensive description of the order statistics of the formulated model is given in section 5. Section 6 considers different entropy measures of the Rayleigh Lomax distribution. Further, the different estimates of the distribution are calculated in section 7. Finally, the model is analyzed using three real life data sets for best fit in section 8 .

\section{Reliability Analysis}

In this section, we derive the survival function, hazard rate and the reverse hazard rate of the proposed generalized Rayleigh Lomax model which are important entities for characterizing real life phenomenon

The survivor function of Rayleigh Lomax distribution is obtained as:

$$
R(x)=1-F(x)=e^{\frac{-\beta}{2}\left(\frac{\theta}{\theta+x}\right)^{-2 \lambda}} .
$$

Figure 3 indicates that the survival function of the model is always a decreasing function for different values of the parameters 


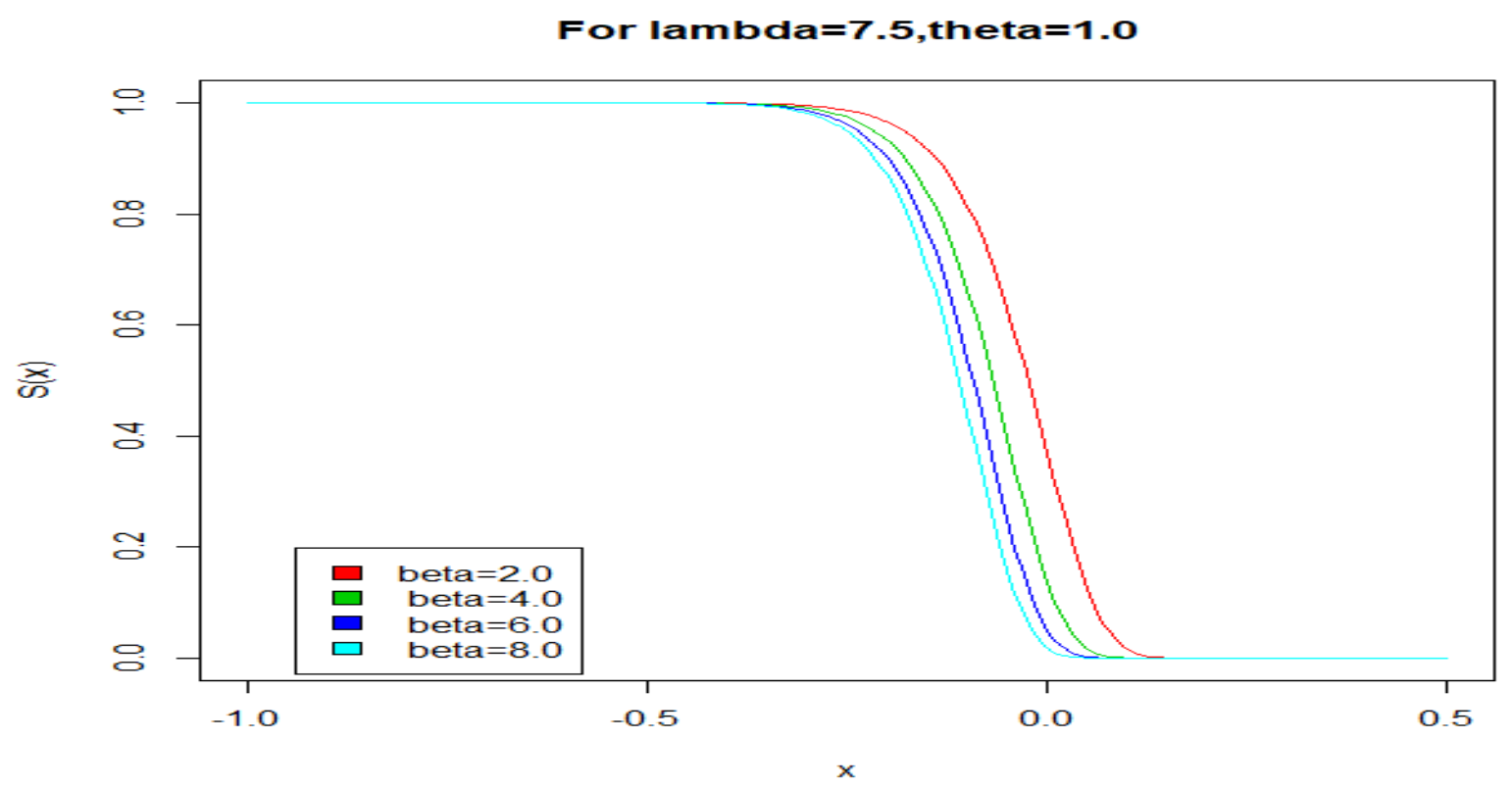

Figure3. Graph of distribution function

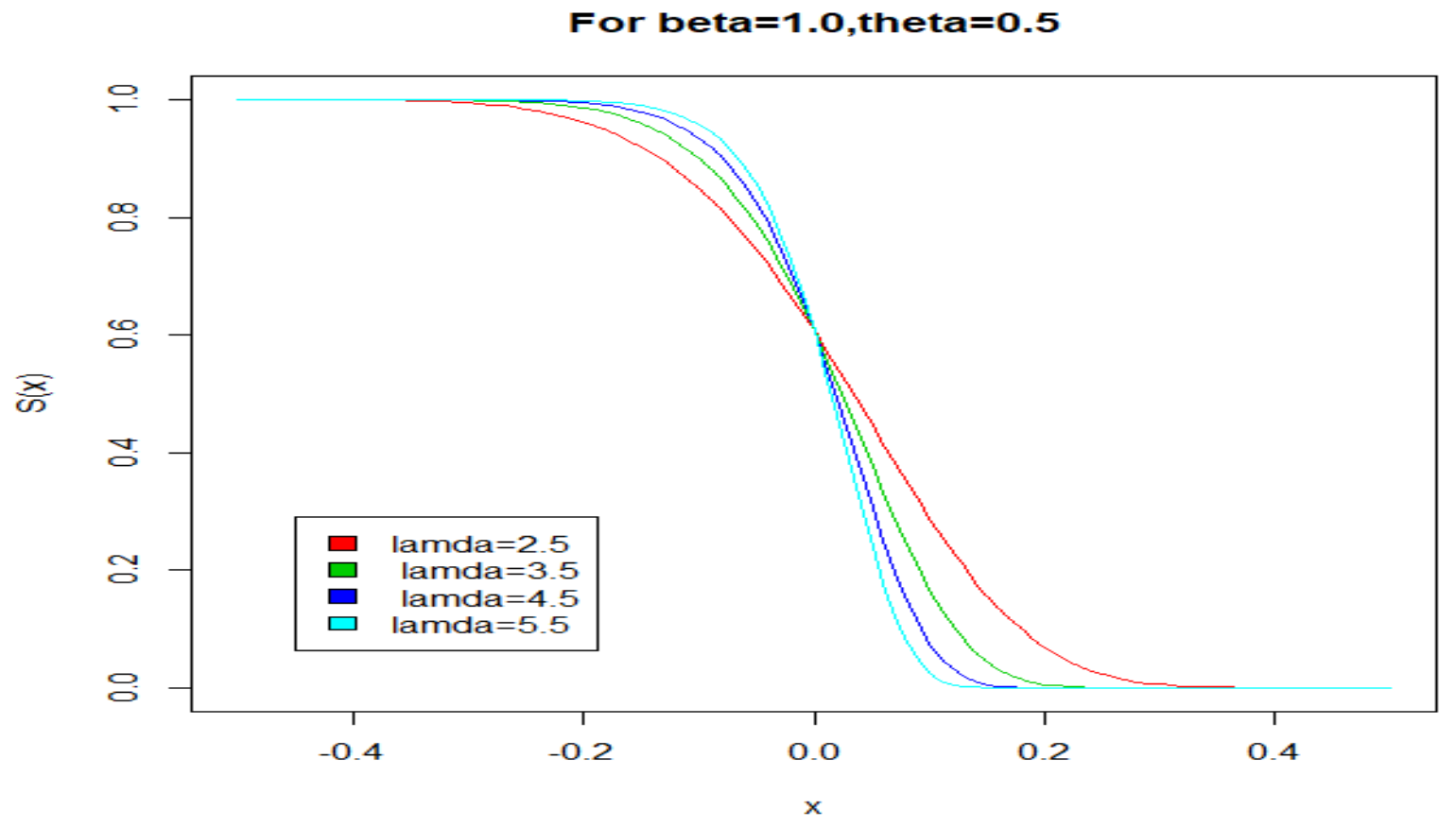

Figure3. Graph of distribution function 


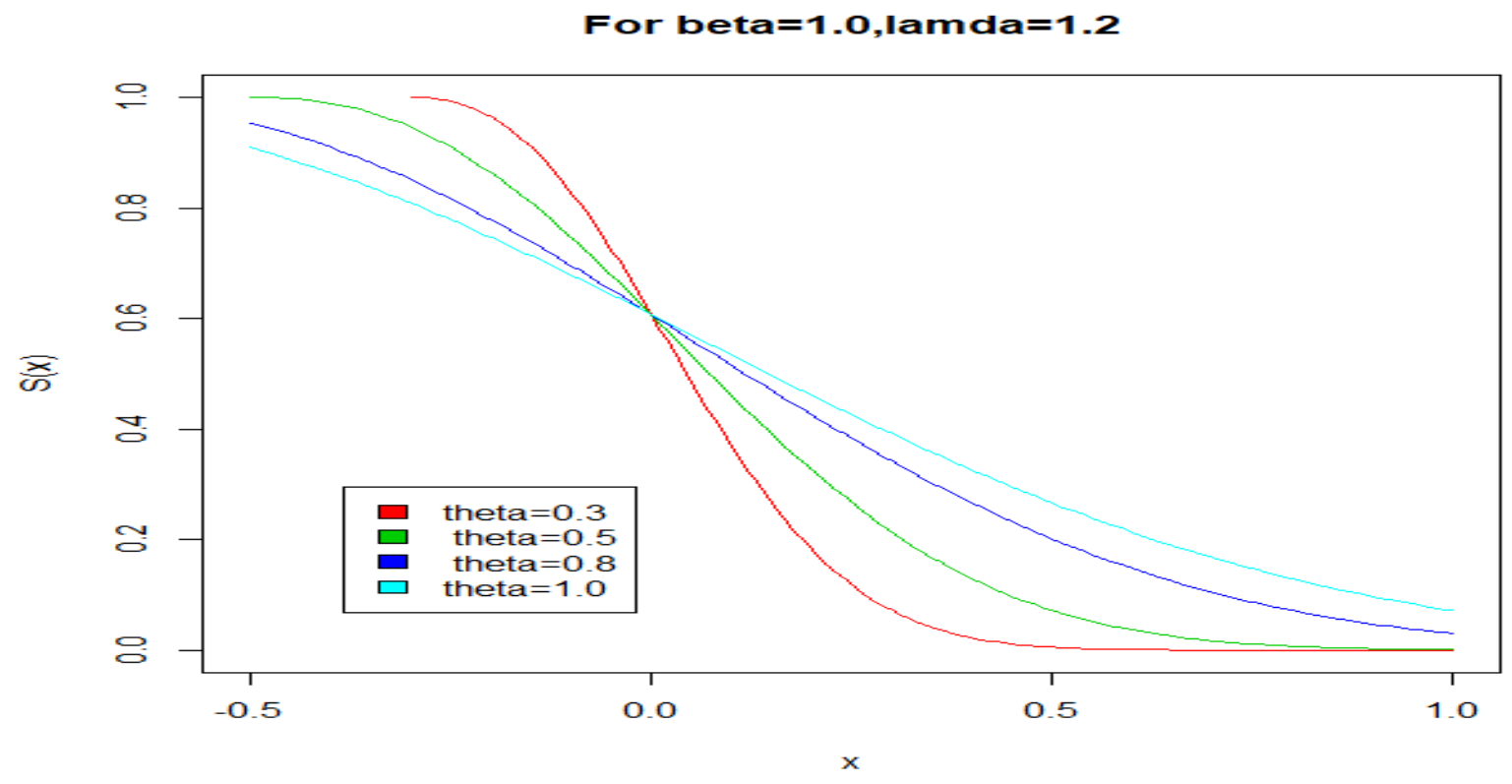

Figure3. Graph of distribution function

The hazard rate and the reverse hazard rate of the model are obtained respectively in the equations (6) and (7) as

$$
\begin{gathered}
h(x)=\frac{f(x)}{R(x)}=\frac{\beta \lambda}{\theta}\left(\frac{\theta}{\theta+x}\right)^{-2 \lambda+1} \\
\text { R.H.R }=\frac{f(x)}{F(x)}=\frac{\frac{\beta \lambda}{\theta}\left(\frac{\theta}{\theta+x}\right)^{-2 \lambda+1} e^{-\frac{\beta}{2}\left(\frac{\theta}{\theta+x}\right)^{-2 \lambda^{--}}}}{1-e^{\frac{-\beta}{2}\left(\frac{\theta}{\theta+x}\right)^{-2 \lambda}}} .
\end{gathered}
$$

\section{Structural properties of Rayleigh Lomax Distribution}

This section deals with the computation of some statistical properties of the Rayleigh Lomax distribution consisting of quantile function, moments, harmonic mean and generating functions which provide a comprehensive description of the proposed model.

\subsection{Quantile function}

The quantile function is widely applicable in statistical study for computation of quartiles and generating random numbers for simulation study. The quantile function is obtained by inverting the equation (3). In this method, we equate the distribution function of the model with a number $u$. The number $\mathrm{u}$ itself follows the uniform distribution.

Suppose $u=F(x)$, where $u \sim U(0,1)$, we have

$$
\Rightarrow \quad u=1-e^{\frac{-\beta}{2}\left(\frac{\theta}{\theta+x}\right)^{-2 \lambda}}
$$




$$
\Rightarrow \quad x=\theta\left[\left\{\frac{-2}{\beta} \log (1-u)\right\}^{\frac{1}{2 \lambda}}-1\right]
$$

For $u=\frac{1}{4}, \frac{1}{2}$ and $\frac{3}{4}$, we obtain the first, second (median) and third quartile of the model respectively.

\subsection{Moments}

If $\mathrm{X}$ is continuous non negative random variable with probability density function $f(x, \beta, \theta, \lambda)$, then the $\mathrm{r}^{\text {th }}$ moment about mean $\mu$ for the given model is obtained by using the following formula:

$$
\mu_{r}=E(X-\mu)^{r}=\int_{-\infty}^{\infty}(x-\mu)^{r} f(x, \beta, \lambda, \theta) d x .
$$

Using the probability density function of the Rayleigh Lomax distribution given in equation (4), we have

$$
\mu_{r}=E(X-\mu)^{r}=\int_{-\theta}^{\infty}(x-\mu)^{r} \frac{\beta \lambda}{\theta}\left(\frac{\theta}{\theta+x}\right)^{-2 \lambda+1} e^{\frac{-\beta}{2}\left(\frac{\theta}{\theta+x}\right)^{-2 \lambda}} d x .
$$

Put $\frac{\beta}{2}\left(\frac{\theta}{\theta+x}\right)^{-2 \lambda}=z, \frac{\beta \lambda}{\theta}\left(\frac{\theta}{\theta+x}\right)^{-2 \lambda+1} d x=d z$, when $x=\infty, z=\infty ; x=-\theta, z=0$.

Also, $\left(\frac{\theta}{\theta+x}\right)^{-2 \lambda}=\frac{2 z}{\beta}$ and $x=\left[\theta\left(\frac{2 z}{\beta}\right)^{\frac{1}{2 \lambda}}-\theta\right]$, we have

$$
E(x-\mu)^{r}=\sum_{j=0}^{\infty}\left({ }^{r} C_{j}\right) \theta^{j}\left(\frac{2}{\beta}\right)^{\frac{j}{2 \lambda}}(-\theta-\mu)^{r-j} \Gamma\left(\frac{j}{2 \lambda}+1\right)
$$

When $\mu=0$, we get the rth moment about the origin of the distribution as follows

$$
\mu_{r}^{\prime}=E(x)^{r}=\sum_{j=0}^{\infty}\left({ }^{r} C_{j}\right) \theta^{j}\left(\frac{2}{\beta}\right)^{\frac{j}{2 \lambda}}(-\theta)^{r-j} \Gamma\left(\frac{j}{2 \lambda}+1\right)
$$

For $r=1$, we get the mean of the proposed model given by

$$
\mu_{1}^{\prime}=E(x)=\sum_{j=0}^{\infty}\left({ }^{1} C_{j}\right) \theta^{j}\left(\frac{2}{\beta}\right)^{\frac{j}{2 \lambda}}(-\theta)^{r-j} \Gamma\left(\frac{j}{2 \lambda}+1\right)
$$

The variance of the distribution is obtained by using the following formula:

$$
\begin{gathered}
\operatorname{Var}(X)=E\left(X^{2}\right)-[E(X)]^{2} \\
\therefore \operatorname{Var}(X)=\sum_{j=0}^{\infty}\left({ }^{2} C_{j}\right) \theta^{j}\left(\frac{2}{\beta}\right)^{\frac{j}{2 \lambda}}(-\theta)^{2-j} \Gamma\left(\frac{j}{2 \lambda}+1\right)-\left[\sum_{j=0}^{\infty}\left({ }^{1} C_{j}\right) \theta^{j}\left(\frac{2}{\beta}\right)^{\frac{j}{2 \lambda}}(-\theta)^{1-j} \Gamma\left(\frac{j}{2 \lambda}+1\right)\right]^{2} .
\end{gathered}
$$




\subsection{Generating Functions}

\section{Moment Generating Function}

The moment generating function of the random variable $\mathrm{X}$ following the Rayleigh Lomax distribution is calculated as follows

$$
M_{X}(t)=E\left(e^{t x}\right)=\int_{0}^{\infty} e^{t x} f(x, \beta, \lambda, \theta) d x .
$$

Using Taylor series

$$
\begin{gathered}
M_{X}(t)=\int_{0}^{\infty}\left(1+t x+\frac{(t x)^{2}}{2 !}+\cdots\right) f(x, \beta, \lambda, \theta) d x . \\
\Rightarrow \quad M_{X}(t)=\sum_{k=0}^{\infty} \frac{t^{k}}{k !} \int_{0}^{\infty} x^{k} f(x, \beta, \lambda, \theta) d x=\sum_{k=0}^{\infty} \frac{t^{k}}{k !} E\left(X^{k}\right) \\
\Rightarrow M_{X}(t)=\sum_{k=0}^{\infty} \frac{t^{k}}{k !} \sum_{j=0}^{\infty}\left({ }^{k} C_{j}\right) \theta^{j}\left(\frac{2}{\beta}\right)^{\frac{j}{2 \lambda}}(-\theta)^{k-j} \Gamma\left(\frac{j}{2 \lambda}+1\right)
\end{gathered}
$$

\section{Cummulant Generating Function}

The cummulant function of the random variable $\mathrm{X}$, denoted by $K_{X}(t)$ is obtained by applying logarithm to the moment generating function given as follows

$$
\begin{gathered}
K_{X}(t)=\log M_{X}(t) \\
K_{X}(t)=\log \left[\sum_{k=0}^{\infty} \frac{t^{k}}{k !} \sum_{j=0}^{\infty}\left({ }^{k} C_{j}\right) \theta^{j}\left(\frac{2}{\beta}\right)^{\frac{j}{2 \lambda}}(-\theta)^{k-j} \Gamma\left(\frac{j}{2 \lambda}+1\right)\right] .
\end{gathered}
$$

\section{Characteristic Function}

By definition of characteristic function we have:

$$
\phi_{X}(t)=E\left(e^{i t x}\right)=\int_{0}^{\infty} e^{i t x} f(x) d x .
$$

Using Taylor series,

$$
\begin{gathered}
\phi_{X}(t)=\int_{0}^{\infty}\left(1+i t x+\frac{(i t x)^{2}}{2 !}+\cdots\right) f(x) d x . \\
\Rightarrow \quad \phi_{X}(t)=\sum_{r=0}^{\infty} \frac{(i t)^{k}}{k !} \int_{0}^{\infty} x^{k} f(x) d x=\sum_{r=0}^{\infty} \frac{(i t)^{k}}{k !} E\left(X^{k}\right) \\
\Rightarrow \quad \phi_{X}(t)=\sum_{k=0}^{\infty} \frac{(i t)^{k}}{k !} \sum_{j=0}^{\infty}\left({ }^{k} C_{j}\right) \theta^{j}\left(\frac{2}{\beta}\right)^{\frac{j}{2 \lambda}}(-\theta)^{k-j} \Gamma\left(\frac{j}{2 \lambda}+1\right)
\end{gathered}
$$

is the characteristic function of the random variable $\mathrm{X}$ following Rayleigh Lomax distribution. 


\section{Order statistics}

Let $X_{1}, X_{2}, \ldots . ., X_{n}$ be a random sample drawn from the population with cumulative density function (cdf) as $\mathrm{F}(\mathrm{x})$ and probability density function (pdf) as $\mathrm{f}(\mathrm{x})$, then the probability density function of the rth order statistics $X_{(1)}, X_{(2)}, \ldots . ., X_{(n)}$ is given as

$$
f_{r}(x)=\frac{n !}{(r-1) !(n-r) !}[F(x)]^{r-1}[1-F(x)]^{n-r} f(x) \quad \text { for } 1 \leq r \leq n
$$

Substituting the equations (3) and (4) in equation (16), we get the probability density function rth order statistics of the Rayleigh Lomax distribution with parameters $(\beta, \lambda, \theta)$ as follows

$$
f_{r}(x)=\frac{n !}{(r-1) !(n-r) !}\left[1-e^{\frac{-\beta}{2}\left(\frac{\theta}{\theta+x}\right)^{-2 \lambda+1}}\right]^{r-1}\left[e^{\frac{-\beta}{2}\left(\frac{\theta}{\theta+x}\right)^{-2 \lambda}}\right]^{n-r} \frac{\beta \lambda}{\theta}\left(\frac{\theta}{\theta+x}\right)^{-2 \lambda+1} e^{\frac{-\beta}{2}\left(\frac{\theta}{\theta+x}\right)^{-2 \lambda}} .
$$

For $r=1$, we get the probability density function of the first order statistics $X_{(1)}=\min \left(X_{1}, X_{2}, \ldots X_{n}\right)$ as follows

$$
f_{1}(x)=\frac{n \beta \lambda}{\theta}\left(\frac{\theta}{\theta+x}\right)^{-2 \lambda+1} e^{-\frac{\beta n}{2}\left(\frac{\theta}{\theta+x}\right)} .
$$

Similarly for $r=n$, we get the probability density function of the nth order statistics $X_{(n)}=\max \left(X_{1}, X_{2}, \ldots X_{n}\right)$ as

$$
f_{n}(x)=\frac{n \beta \lambda}{\theta}\left(\frac{\theta}{\theta+x}\right)^{-2 \lambda+1}\left[1-e^{-\frac{\beta}{2}\left(\frac{\theta}{\theta+x}\right)^{-2 \lambda}}\right]^{n-1} e^{\frac{-\beta}{2}\left(\frac{\theta}{\theta+x}\right)^{-2 \lambda}}
$$

Also, when $n=2 m$ in equation (), the pdf of the median $(m+1)$ of the Rayleigh Lomax distribution is obtained as follows

$$
\begin{gathered}
f_{(m+1)}(x)=\frac{(2 m+1) !}{m ! m !}[F(x)]^{m-1}[1-F(x)]^{m-1} f(x) . \\
f_{(m+1)}(x)=\frac{(2 m+1) !}{m ! m !}\left[1-e^{\frac{-\beta}{2}\left(\frac{\theta}{\theta+x}\right)^{-2 \lambda+1}}\right]^{m-1}\left[e^{\frac{-\beta}{2}\left(\frac{\theta}{\theta+x}\right)^{-2 \lambda}}\right]^{m-1} \frac{\beta \lambda}{\theta}\left(\frac{\theta}{\theta+x}\right)^{-2 \lambda+1} e^{\frac{-\beta}{2}\left(\frac{\theta}{\theta+x}\right)^{-2 \lambda}} .
\end{gathered}
$$

\section{$5.1 \quad$ Joint density function}

The joint probability density function of $\left(x_{i}, x_{j}\right)$ for $1 \leq i \leq j \leq n$ is given by:

$$
f_{i: j: n}\left(x_{i}, x_{j}\right)=C\left[F\left(x_{i}\right)\right]^{i-1}\left[F\left(x_{j}\right)-F\left(x_{i}\right)\right]^{j-i-1}\left[1-F\left(x_{j}\right)\right]^{n-j} f\left(x_{i}\right) f\left(x_{j}\right)
$$

where

$$
C=\frac{n !}{(i-1) !(j-i-1) !(n-j) !}
$$


Then, the joint distribution function of the ith and jth order statistics of Rayleigh Lomax distribution is as follows:

$$
f_{i: j: n}\left(x_{i}, x_{j}\right)=C\left[1-h\left(x_{i}\right)\right]^{i-1}\left[h\left(x_{j}\right)-h\left(x_{i}\right)\right]^{j-i-1}\left[h\left(x_{j}\right)\right]^{n-j} \frac{\beta \lambda}{\theta}\left[\frac{\theta}{\theta+x_{i}}\right]^{-2 \lambda+1} h\left(x_{i}\right) \frac{\beta \lambda}{\theta}\left[\frac{\theta}{\theta+x_{j}}\right]^{-2 \lambda+1} h\left(x_{j}\right),
$$

where $h(x)=e^{\frac{-\beta}{2}\left(\frac{\theta}{\theta+x}\right)^{-2 \lambda}}$

For the special case $i=1$ and $j=n$, the joint density function of minimum and maximum order statistics is as follows:

$$
\begin{gathered}
f_{1 n}(x)=n(n-1)\left[F\left(x_{n}\right)-F\left(x_{1}\right)\right]^{n-2} f\left(x_{1}\right) f\left(x_{n}\right) . \\
f_{1, n}\left(x_{1}, x_{n}\right)=n(n-1)\left[h\left(x_{n}\right)-h\left(x_{1}\right)\right]^{n-2} \frac{\beta \lambda}{\theta}\left[\frac{\theta}{\theta+x_{1}}\right]^{-2 \lambda+1} h\left(x_{1}\right) \frac{\beta \lambda}{\theta}\left[\frac{\theta}{\theta+x_{n}}\right]^{-2 \lambda+1} h\left(x_{n}\right) .
\end{gathered}
$$

\section{Information Measures}

The entropy is a measure of the variation of the uncertainty of a continuous random variable X. In this section, different entropy measures comprising of Renyi entropy, q-entropy and Shannon entropy for the formulated Rayleigh-Lomax model are discussed.

\subsection{Renyi entropy}

The Renyi entropy [18] is denoted by $I_{R}(\rho)$ and can be calculated as

$$
I_{R}(\rho)=\frac{1}{1-\rho} \log \int_{-\infty}^{\infty} f(x)^{\rho} d x, \text { where } \rho>0 \text { and } \rho \neq 1
$$

when the expression for $\mathrm{f}(\mathrm{x})$ is given in the equation (4)

For the convenience, let $u(x)=\int_{-\theta}^{\infty} f(x)^{\rho} d x$.

$$
\Rightarrow u(x)=\int_{-\theta}^{\infty}\left(\frac{\lambda \beta}{\theta}\right)^{\rho}\left(\frac{\theta}{\theta+x}\right)^{\rho(-2 \lambda+1)} e^{\frac{-\beta \rho}{2}\left(\frac{\theta}{\theta+x}\right)^{-2 \lambda}} d x
$$

Put $\frac{\beta}{2}\left(\frac{\theta}{\theta+x}\right)^{-2 \lambda}=z, \frac{\lambda \beta}{\theta}\left(\frac{\theta}{\theta+x}\right)^{-2 \lambda+1} d x=d z$.

When $x=\infty, z=\infty ; x=-\theta, z=0$. Also, $\left(\frac{\theta}{\theta+x}\right)=\left(\frac{2 z}{\beta}\right)^{\frac{-1}{2 \lambda}}$, then we have

$$
u(x)=\left(\frac{\lambda \beta}{\theta}\right)^{\rho-1}\left(\frac{2}{\beta}\right)^{\frac{(2 \lambda-1)(\rho-1)}{2 \lambda}} \frac{\left(\frac{(2 \lambda-1)(\rho-1)}{2 \lambda}+1\right)}{\rho^{\frac{(2 \lambda-1)(\rho-1)}{2 \lambda}+1}} .
$$

Substituting the value of equation (24) in (23) we get the Renyi entropy of Rayleigh Lomax distribution as follows: 


$$
I_{R}(\rho)=-\log \lambda-\log \beta+\log \theta+\left(\frac{1}{2 \lambda}-1\right) \log \left(\frac{2}{\beta}\right)+\frac{1}{1-\rho} \log \left[\frac{\Gamma\left(\frac{(2 \lambda-1)(\rho-1)}{2 \lambda}+1\right)}{\rho^{\frac{(2 \lambda-1)(\rho-1)}{2 \lambda}+1}}\right]
$$

$\therefore I_{R}(\rho)=-\log \lambda-\left(\frac{1}{2 \lambda}\right) \log \beta+\log \theta+\left(\frac{1}{2 \lambda}-1\right) \log 2$

$$
+\frac{1}{1-\rho} \log \Gamma\left(\frac{(2 \lambda-1)(\rho-1)}{2 \lambda}+1\right)-\frac{(2 \lambda-1)(\rho-1)+2 \lambda}{2 \lambda(1-\rho)} \log \rho .
$$

\section{2 q- entropy}

The $\beta$ or q-entropy introduced by Havrda and Charvat[19] is denoted by $I_{H}(q)$ and can be computed as:

$$
\begin{gathered}
I_{H}(q)=\frac{1}{q-1}\left\{1-\int_{-\infty}^{\infty} f(x)^{q} d x\right\} \text {, where } q>0 \text { and } q \neq 1 \\
I_{R}(q)=\frac{1}{1-q}\left\{1-\int_{-\theta}^{\infty}\left(\frac{\beta \lambda}{\theta}\right)^{q}\left(\frac{\theta}{\theta+x}\right)^{q(-2 \lambda+1)} e^{-\frac{q \beta}{2}\left(\frac{\theta}{\theta+x}\right)^{-2 \lambda}} d x\right\} . \\
\therefore I_{R}(q)=\frac{1}{1-q}\left\{1-\left(\frac{\beta \lambda}{\theta}\right)^{q}\left(\frac{2}{\beta}\right)^{\frac{(2 \lambda-1)(q-1)}{2 \lambda}} \frac{\Gamma\left(\frac{(2 \lambda-1)(q-1)}{2 \lambda}+1\right)}{\frac{(2 \lambda-1)(q-1)}{2 \lambda}+1}\right\} .
\end{gathered}
$$

\subsection{Shannon Entropy}

The Shannon entropy[20] is a special case of the Renyi entropy when $\rho \rightarrow 1$.It is denoted by $H(x)$ and is defined as follows

$$
\begin{gathered}
H(x)=E[-\log f(x)] \\
=E\left[-\log \beta-\log \lambda+\log \theta-(-2 \lambda+1) \log \left(\frac{\theta}{\theta+x}\right)+\frac{\beta}{2}\left(\frac{\theta}{\theta+x}\right)^{-2 \lambda}\right] \\
\Rightarrow H(x)=-\log \beta-\log \lambda+\log \theta-(-2 \lambda+1) I_{1}+\frac{\beta}{2} I_{2} .
\end{gathered}
$$

where $I_{1}=E\left[\log \left(\frac{\theta}{\theta+x}\right)\right]$ and $I_{2}=E\left[\frac{\theta}{\theta+x}\right]^{-2 \lambda}$. 
Now $I_{1}=E\left[\log \left(\frac{\theta}{\theta+x}\right)\right]=\int_{-\theta}^{\infty} \log \left(\frac{\theta}{\theta+x}\right) f(x) d x$
$=\int_{-\theta}^{\infty} \log \left(\frac{\theta}{\theta+x}\right) \frac{\beta \lambda}{\theta}\left(\frac{\theta}{\theta+x}\right)^{-2 \lambda+1} e^{-\frac{\beta}{2}\left(\frac{\theta}{\theta+x}\right)^{-2 \lambda}} d x$.

Put $\frac{\beta}{2}\left(\frac{\theta}{\theta+x}\right)^{-2 \lambda}=z,\left(\frac{\theta}{\theta+x}\right)=\left(\frac{2 z}{\beta}\right)^{\frac{1}{2 \lambda}}, \frac{\lambda \beta}{\theta}\left(\frac{\theta}{\theta+x}\right)^{-2 \lambda+1} d x=d z$,

We have $I_{1}=E\left[\log \left(\frac{\theta}{\theta+x}\right)\right]=\frac{-1}{2 \lambda} \log \left(\frac{2}{\beta}\right)-\frac{1}{2 \lambda} \Gamma^{\prime}(1)$.

Also, $I_{2}=E\left[\frac{\theta}{\theta+x}\right]^{-2 \lambda}=\frac{2}{\beta}$.

$$
\therefore H(x)=-\log \beta-\log \lambda+\log \theta-(-2 \lambda+1)\left[\frac{-1}{2 \lambda} \log \left(\frac{2}{\beta}\right)-\frac{1}{2 \lambda} \Gamma^{\prime}(1)\right]+1 \text {. }
$$

\section{Maximum Likelihood Estimation}

For estimating the unknown parameters of the Rayleigh Lomax distribution, the technique of maximum likelihood estimation is used. The maximum likelihood estimates (MLE's) of the parameters of the proposed distribution are obtained as follows:

Consider the random sample $x_{1}, x_{2}, \ldots . . x_{n}$ drawn from the Rayleigh Lomax distribution. Then, the likelihood function and the corresponding log likelihood function of the equation (4) are respectively given as in the equations

$$
L(x \mid \theta, \lambda, \beta)=\left(\frac{\lambda \beta}{\theta}\right)^{n} \prod_{i=1}^{n}\left(\frac{\theta}{\theta+x}\right)^{-2 \lambda+1} e^{\frac{-\beta}{2} \sum_{i=1}^{n}\left(\frac{\theta}{\theta+x}\right)^{-2 \lambda}}
$$

$\log L(x \mid \theta, \lambda, \beta)=n \log \lambda+n \log \beta-n \log \theta+(-2 \lambda+1) \sum_{i=1}^{n} \log \left(\frac{\theta}{\theta+x}\right)-\frac{\beta}{2} \sum_{i=1}^{n}\left(\frac{\theta}{\theta+x}\right)^{-2 \lambda}$.

Differentiating the Log Likelihood function in equation () with respect to the three unknown parameters and equating them to zero, we get the three respective normal equations as follows:

$$
\begin{gathered}
\frac{d}{d \lambda} \log L(x \mid \theta, \lambda, \beta)=\frac{n}{\lambda}-2 \sum_{i=1}^{n} \log \left(\frac{\theta}{\theta+x}\right)-\frac{\beta}{2} \sum_{i=1}^{n}\left(\frac{\theta}{\theta+x}\right)^{-2 \lambda}\left(-2 \log \left(\frac{\theta}{\theta+x}\right)\right)=0 \\
\frac{d}{d \beta} \log L(x \mid \theta, \lambda, \beta)=\frac{n}{\beta}-\frac{1}{2} \sum_{i=1}^{n}\left(\frac{\theta}{\theta+x}\right)^{-2 \lambda}=0 \\
\frac{d}{d \theta} \log L(x \mid \theta, \lambda, \beta)=\frac{-n}{\theta}+(-2 \lambda+1) \sum_{i=1}^{n} \frac{x}{\theta(\theta+x)}+\frac{\beta \lambda}{\theta^{2}} \sum_{i=1}^{n} x\left(\frac{\theta}{\theta+x}\right)^{-2 \lambda+1}=0
\end{gathered}
$$

The solutions obtained by solving the three normal equations simultaneously represent the maximum likelihood estimates of unknown parameters $(\lambda, \beta, \theta)$ of the proposed distribution. 


\section{Data Analysis}

In this section, we consider the following three real life data sets to test the flexibility and efficiency of the proposed model over other generalized models i.e. Gumbel Lomax, Weibull Lomax and Exponential Lomax. For comparison, three different information criteria like AIC (Akaike information criterion) and BIC (Bayesian information criterion) are used which can be computed as

$$
\mathrm{AIC}=2 \mathrm{k}-2 \log \mathrm{L}, \mathrm{BIC}=\mathrm{k} \log \mathrm{n}-2 \log \mathrm{L}
$$

where $\mathrm{k}$ is the number of parameters in the statistical model, $\mathrm{n}$ is the sample size and $2 \log \mathrm{L}$ is the maximized value of the $\log$-likelihood function under the considered model. The distribution which provides us lesser values of AIC and BIC is considered as best. The analysis of the data sets is performed through R software. The MLEs of the parameters are obtained with standard errors shown in parentheses. The summary of the three data sets are presented in the tables 1,2 and 3 respectively. Further the corresponding log-likelihood values, AIC and BIC are displayed in Table 4.

The pdf of Gumbel Lomax is defined and is given by

$$
f(x)=\frac{\alpha \beta\left(\frac{x+\theta}{\theta}\right)^{\frac{-\alpha}{\lambda}-1} \exp \left\{-\beta\left[\left(\frac{x+\theta}{\theta}\right)^{\alpha}-1\right]^{\frac{-1}{\lambda}}\right\}}{\theta \lambda\left\{1-\left(\frac{x+\theta}{\theta}\right)^{-\alpha}\right\}^{\frac{1}{\lambda}+1}} \alpha, \beta, \lambda, \theta, x>0
$$

The pdf of Weibull Lomax is defined and is given by

$$
f(x)=\frac{\alpha \beta \lambda}{\theta}\left(1+\frac{x}{\theta}\right)^{\beta \lambda-1}\left[1-\left(1+\frac{x}{\theta}\right)^{-\lambda}\right]^{\beta-1} \exp \left[-\alpha\left[\left(1+\frac{x}{\theta}\right)^{\lambda}-1\right]^{\beta}\right] \quad \alpha, \beta, \lambda, \theta, x>0
$$

The pdf of Exponential Lomax is defined and is given by

$$
f(x)=\frac{\alpha \lambda}{\theta}\left(\frac{\theta}{x+\theta}\right)^{-\alpha+1} e^{-\lambda\left(\frac{\theta}{x+\theta}\right)^{-\alpha}} ; x \geq-\theta, \alpha, \theta, \lambda>0 .
$$

The pdf of Rayleigh Lomax is defined and is given by

$$
f(x)=\frac{\alpha \lambda}{\theta}\left(\frac{\theta}{x+\theta}\right)^{-2 \alpha+1} e^{-\frac{\lambda}{2}\left(\frac{\theta}{x+\theta}\right)^{-2 \alpha}} ; x \geq-\theta, \alpha, \theta, \lambda>0
$$

Data set I: The first data set is the failure times of 84 Aircraft Windshield. The windshield on a large aircraft is a complex piece of equipment, comprised basically of several layers of material, including a very strong outer skin with a heated layer just beneath it, all laminated under high temperature and pressure. Failures of these items are not structural failures. Instead, they typically involve damage or delamination of the nonstructural outer ply or failure of the heating system. These failures do not result in damage to the aircraft but do result in replacement of the windshield. These data on failure times are reported in the book "Weibull Models" by Murthy et al. (2004, page 297).

$0.040,1.866,2.385,3.443,0.301,1.876,2.481,3.467,0.309,1.899,2.610,3.478,0.557,1.911,2.625$, $3.578,0.943,1.912,2.632,3.595,1.070,1.914,2.646,3.699,1.124,1.981,2.661,3.779,1.248,2.010$, $2.688,3.924,1.281,2.038,2.82,3,4.035,1.281,2.085,2.890,4.121,1.303,2.089,2.902,4.167,1.432$, 2.097, 2.934, 4.240, 1.480, 2.135, 2.962, 4.255, 1.505, 2.154, 2.964, 4.278, 1.506, 2.190, 3.000, 4.305, $1.568,2.194,3.103,4.376,1.615,2.223,3.114,4.449,1.619,2.224,3.117,4.485,1.652,2.229,3.166$, $4.570,1.652,2.300,3.344,4.602,1.757,2.324,3.376,4.66$ 
Data Set II This data set contains observations on the strengths of $1.5 \mathrm{~cm}$ glass fibers, measured at the National Physical Laboratory, England. The observations are: $0.55,0.93,1.25,1.36,1.49,1.52,1.58$, $1.61,1.64,1.68,1.73,1.81,2,0.74,1.04,1.27,1.39,1.49,1.53,1.59,1.61,1.66,1.68,1.76,1.82,2.01$, $0.77,1.11,1.28,1.42,1.5,1.54,1.6,1.62,1.66,1.69,1.76,1.84,2.24,0.81,1.13,1.29,1.48,1.5,1.55$, $1.61,1.62,1.66,1.7,1.77,1.84,0.84,1.24,1.3,1.48,1.51,1.55,1.61,1.63$.

Data Set III The third data is on the breaking stress of carbon fibres of $50 \mathrm{~mm}$ length (GPa). The data has been previously used by Nichols and Padgett [21]. The data is as follows: 0.39, 0.85, 1.08, 1.25, 1.47, $1.57, \quad 1.61, \quad 1.61, \quad 1.69 \quad 1.80, \quad 1.84,1.87 \quad 1.89 \quad 2.03 \quad 2.03 \quad 2.05 \quad, 2.12, \quad 2.35 \quad, 2.41$, 2.43,2.48,2.50,2.5, 2.55, 2.55, 2.56, 2.59, 2.67, $2.73,2.74,2.79,2.81,2.82,2.85$,2.87,2.88 ,2.93,2.95,2.96,

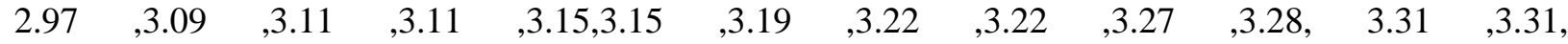
$3.33,3.39,3.39,3.56,3.60,3.65,3.68,3.70,3.75,4.20,4.38,4.42,4.70,4.90$.

Table 1: Data summary for the Data set first

\begin{tabular}{|l|l|l|l|l|l|l|l|l|}
\hline Min. & 1st Qu. & Median & Mean & 3rd Qu. & Max. & Variance & Skewness & Kurtosis \\
\hline 0.040 & 1.866 & 2.385 & 2.563 & 3.376 & 4.663 & 1.239 & 0.0865 & 2.365 \\
\hline
\end{tabular}

Table 2: Data summary for the Data set second

\begin{tabular}{|l|l|l|l|l|l|l|l|l|}
\hline Min. & 1st Qu. & Median & Mean & 3rd Qu. & Max. & Variance & Skewness & Kurtosis \\
\hline 0.550 & 1.375 & 1.590 & 1.507 & 1.685 & 2.240 & 0.1051 & -0.8999 & 3.9237 \\
\hline
\end{tabular}

Table 3: Data summary for the Data set third

\begin{tabular}{|l|l|l|l|l|l|l|l|l|}
\hline Min. & 1st Qu. & Median & Mean & 3rd Qu. & Max. & Variance & Skewness & Kurtosis \\
\hline 0.390 & 2.178 & 2.835 & 2.760 & 3.278 & 4.900 & 0.7947 & -0.1315 & 3.2230 \\
\hline
\end{tabular}

Table 4: MLEs of the model parameters using real data sets, the resulting SEs in parentheses and Criteria for Comparison

\begin{tabular}{|c|c|c|c|c|c|c|c|c|}
\hline \multirow{5}{*}{$\begin{array}{l}\text { Data } \\
\text { Set I }\end{array}$} & Distribution & $\alpha$ & $\beta$ & $\lambda$ & $\theta$ & $\begin{array}{c}\text { Log- } \\
\text { likelihood }\end{array}$ & AIC & BIC \\
\hline & $\begin{array}{l}\text { Gumbel } \\
\text { Lomax }\end{array}$ & $\begin{array}{c}563.799 \\
(183.729)\end{array}$ & $\begin{array}{c}6.6535 \\
(1.0373) \\
\end{array}$ & $\begin{array}{c}8.6253 \\
(2.6213) \\
\end{array}$ & $\begin{array}{l}254.9907 \\
(14.7717) \\
\end{array}$ & -132.6742 & 273.3484 & 283.119 \\
\hline & $\begin{array}{l}\text { Weibull } \\
\text { Lomax }\end{array}$ & $\begin{array}{c}0.0148 \\
(0.0163)\end{array}$ & $\begin{array}{c}0.8600 \\
(0.7545) \\
\end{array}$ & $\begin{array}{c}4.7605 \\
(4.2036)\end{array}$ & $\begin{array}{c}1.6441 \\
(1.5376)\end{array}$ & -127.9247 & 263.8495 & 273.6201 \\
\hline & $\begin{array}{l}\text { Exponential- } \\
\text { Lomax }\end{array}$ & $\begin{array}{c}2.8875 \\
(0.4158) \\
\end{array}$ & - & $\begin{array}{c}0.0049 \\
(0.0017)\end{array}$ & $\begin{array}{c}0.5465 \\
(0.2130) \\
\end{array}$ & -128.9293 & 263.8586 & 271.1866 \\
\hline & $\begin{array}{c}\text { Rayleigh } \\
\text { Lomax }\end{array}$ & $\begin{array}{c}1.5977 \\
(0.2509) \\
\end{array}$ & - & $\begin{array}{c}0.0093 \\
(0.0061) \\
\end{array}$ & $\begin{array}{c}0.6678 \\
(0.3221) \\
\end{array}$ & -128.6271 & 263.2542 & 270.5822 \\
\hline \multirow{4}{*}{$\begin{array}{c}\text { Data } \\
\text { Set } \\
\text { II }\end{array}$} & $\begin{array}{l}\text { Gumbel } \\
\text { Lomax }\end{array}$ & $\begin{array}{c}313.8864 \\
(330.0425)\end{array}$ & $\begin{array}{c}9.3657 \\
(9.8963)\end{array}$ & $\begin{array}{c}134.858 \\
(15.4020)\end{array}$ & $\begin{array}{c}3.2246 \\
(3.5346)\end{array}$ & -30.52894 & 69.05788 & 77.63042 \\
\hline & $\begin{array}{l}\text { Weibull } \\
\text { Lomax }\end{array}$ & $\begin{array}{c}0.0203 \\
(0.0313) \\
\end{array}$ & $\begin{array}{c}4.3636 \\
(1.1339) \\
\end{array}$ & $\begin{array}{c}2.2780 \\
(2.2198) \\
\end{array}$ & $\begin{array}{l}2.2686 \\
(2.8216) \\
\end{array}$ & -14.71666 & 37.43331 & 46.00585 \\
\hline & $\begin{array}{l}\text { Exponential- } \\
\text { Lomax }\end{array}$ & $\begin{array}{c}8.3482 \\
(5.6564) \\
\end{array}$ & - & $\begin{array}{c}0.1448 \\
(0.1137) \\
\end{array}$ & $\begin{array}{l}7.7811 \\
(5.9329) \\
\end{array}$ & -15.40364 & 36.80728 & 43.23668 \\
\hline & $\begin{array}{c}\text { Rayleigh } \\
\text { Lomax }\end{array}$ & $\begin{array}{c}9.6906 \\
(4.5154) \\
\end{array}$ & - & $\begin{array}{c}0.0036 \\
(0.0012) \\
\end{array}$ & $\begin{array}{c}4.2267 \\
(2.3856) \\
\end{array}$ & -15.08599 & 36.17197 & 42.60138 \\
\hline \multirow{4}{*}{$\begin{array}{l}\text { Data } \\
\text { Set } \\
\text { III }\end{array}$} & $\begin{array}{l}\text { Gumbel } \\
\text { Lomax }\end{array}$ & $\begin{array}{l}428.8866 \\
(71.3809) \\
\end{array}$ & $\begin{array}{c}3.3989 \\
(2.6736) \\
\end{array}$ & $\begin{array}{l}268.7253 \\
(27.2118) \\
\end{array}$ & $\begin{array}{c}5.3683 \\
(1.9985) \\
\end{array}$ & -92.43192 & 192.8638 & 201.6225 \\
\hline & $\begin{array}{l}\text { Weibull } \\
\text { Lomax }\end{array}$ & $\begin{array}{c}0.0224 \\
(0.0465)\end{array}$ & $\begin{array}{c}2.3421 \\
(1.0304)\end{array}$ & $\begin{array}{c}2.2876 \\
(2.1628)\end{array}$ & $\begin{array}{l}2.57732 \\
(3.1711) \\
\end{array}$ & -85.73845 & 179.4769 & 188.2355 \\
\hline & $\begin{array}{l}\text { Exponential- } \\
\text { Lomax }\end{array}$ & $\begin{array}{c}7.4794 \\
(4.5443) \\
\end{array}$ & - & $\begin{array}{c}0.0079 \\
(0.0064)\end{array}$ & $\begin{array}{r}3.4435 \\
(3.5638) \\
\end{array}$ & -86.80417 & 179.6083 & 186.1773 \\
\hline & $\begin{array}{c}\text { Rayleigh } \\
\text { Lomax }\end{array}$ & $\begin{array}{c}2.6666 \\
(0.6543) \\
\end{array}$ & - & $\begin{array}{c}0.0067 \\
(0.0036)\end{array}$ & $\begin{array}{c}1.6113 \\
(0.8103)\end{array}$ & -86.03488 & 178.0698 & 184.6387 \\
\hline
\end{tabular}



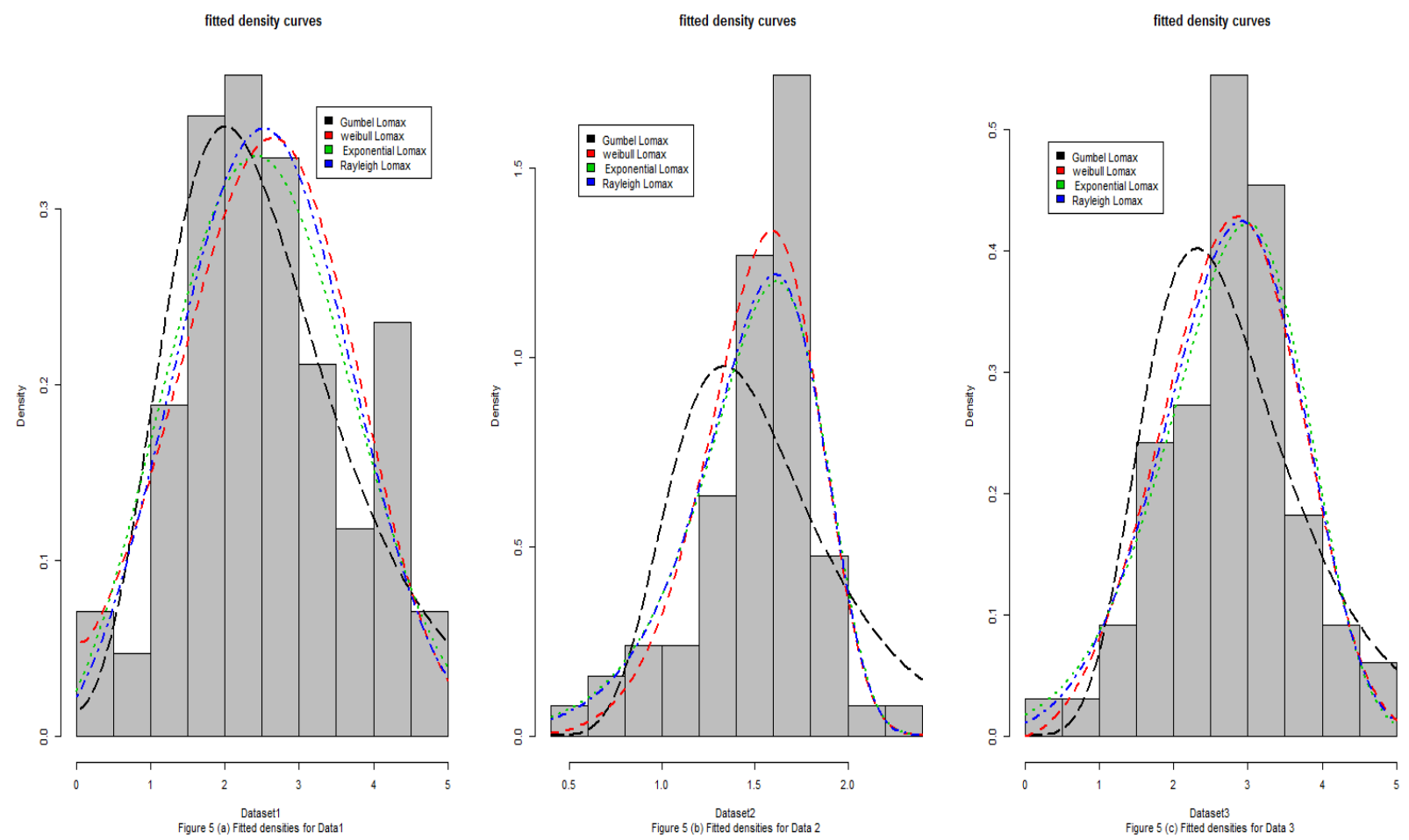

Figure 4: Graphs of the fitted Rayleigh Lomax (RL), Gumbul Lomax (GuL),Weibull Lomax(WL), Exponential Lomax (EL) and distributions for data sets 1,2 and 3 .

\section{Conclusion}

From the table 4, it is clearly evident that our proposed Rayleigh Lomax model has lesser values of AIC and BIC for the three data sets considered in comparison with other generalized models already studied. As such, it can be inferred that our model is much flexible and can be used for analyzing real life phenomena for better fitting. 


\section{References}

[1] Lomax, K.S. (1954). Business failures: Another example of the analysis of failure data, Journal of the American Statistical Association. 49, 847-852.

[2] Bryson, M.C. (1974). Heavy-tailed distribution: properties and tests, Technometrics 16, 16168.

[3] Atkinson, A. B. and Harrison, A. J. (1978). Distribution of Personal Wealth in Britain (Cambridge University Press, Cambridge).

[4] Hassan, A. S. and Al-Ghamdi, A. S. (2009). Optimum step stress accelerated life testing for Lomax distribution, Journal of Applied Sciences Research 5, 2153-2164.

[5] Siddiqui, M. M. (1962). Some problems connected with Rayleigh distributions. J. Res. Nat. Bur. Stand, 60D, 167-174.

[6] Howlader, H. A. and Hossain, A. (1995). On Bayesian estimation and prediction from Rayleigh distribution based on type-II censored data. Communications in Statistics- Theory and Methods, 24(9), 2249-2259.

[7] Lalitha, S. and Mishra, A. (1996). Modified maximum likelihood estimation for Rayleigh distribution, Comm. Stat. Theory Methods, 25, 389-401.

[8] Abd Elfattah, A.M., Hassan, A. S and Ziedan, D.M. (2006). Efficiency of Maximum Likelihood Estimators under Different Censored Sampling Schemes for Rayleigh Distribution. Interstat.

[9] Marshall, A.M., Olkin, I. (1997). A new method for adding a parameter to a family of distributions with applications to the exponential and Weibull families, Biometrika, 84(3), 641-652.

[10]Cordeiro, G.M. and de Castro, M. (2011). A new family of generalized distributions, Journal of Statistical Computation and Simulation, 81, 883-893.

[11]Eugene, N., Lee, C. and Famoye, F. (2002). Beta-normal distribution and its applications. Communications in Statistics-Theory and Methods, 31 (6), 497-512.

[12] Alexander, C., Cordeiro, G. M., Ortega, E.M.M. and Sarabia, J. M. (2012). Generalized beta generated distributions, Computational Statistics and Data Analysis, 56, 1880-1897.

[13] Shaw, W. and Buckley, I. (2009) The Alchemy of Probability Distributions: Beyond Gram-Charlier Expansions, and a Skew-Kurtotic-Normal Distribution from a Rank Transmutation Map. Research Report.

[14] Alzaatreh, A., Lee, C. and Famoye, F. (2013) A new method for generating families of continuous distributions. Metron, 71(1), 63-79. 
[15] Tahir, M.H., Cordeiro, G. M., Mansoor, M., Alzaatreh, A. and Zubair, M. A. (2018). New Generalized Family of Distributions from Bounded Support. Journal of Data Science, 16(2), 251-256.

[16]Tahir, M. H., Hussain, M. A., Cordeiro, G. M., Hamedani, G.G., Mansoor, M. and Zubair, M. (2016). The Gumbel-Lomax Distribution: Properties and Applications. Journal of Statistical Theory and Applications, 15(1), 61-79.

[17] Tahir, M. H., Cordeiro, G. M., Mansoor, M. and Zubair, M. (2015). The Weibull-Lomax distribution: Properties and Applications. Hacettepe Journal of Mathematics and Statistics, 44 (2), 461 - 480.

[18]El-Bassiouny, A. H., Abdo, N. F. and Shahen, H. S. (2015). Exponential Lomax Distribution. International Journal of Computer Applications. 121(13), 24-29.

[19]Hassan, A. S. and Abd-Allah, M. (2018). Exponentiated Weibull-Lomax Distribution: Properties and Estimation, Journal of Data Science, 16(2), 277-298.

[20]Hassan, A. S. and Nassr, S. G. (2018). Power Lomax Poisson distribution: Properties and Applications, Journal of Data Science, 16(1), 105-128.

[21]R'enyi, A. (1961).On measures of entropy and information, In: 4th Berkeley Symposium on Mathematical Statistics and Probability, 1, 547-561.

[22] Havrda, J. and Charvát, F. (1967). Quantification Method of Classification Processes. Concept of Structural -Entropy. Kybernetika, 3, 30-35.

[23] Shannon, C.E. (1948). A mathematical theory of communication, Bell System Technical Journal 27, 379-432.

[24] Murthy, DNP., Xi, M., and Jiangs, R. (2004). Weibull models, Wiley, Hoboken, 297.

[25] Nicholas, M. D., Padgett W. J. (2006). A bootstrap control chart for Weibull percentiles. Quality and Reliability Engineering International, 22, 141-151. 